\title{
Seasonal streamflow prediction using large scale climate drivers for NSW region
}

\author{
$\underline{\text { R.I. Esha }}^{a}$ and M.A. Imteaz ${ }^{\mathrm{a}}$ \\ ${ }^{a}$ Department of Civil and Construction Engineering, Swinburne University of Technology, Melbourne, \\ Australia \\ Email: resha@swin.edu.au
}

\begin{abstract}
High inter-annual variability of streamflow resulting from the extensive topographic variation and climatic inconsistency cause immense difficulties to the water planners and managers of New south Wales which is one of the major contributors of Australia's agricultural production. Therefore, in this study an attempt is made to develop a skilful seasonal streamflow forecast method considering four major influential climate variables (ENSO, PDO, IOD, IPO) of south-east New South Wales. Single lagged correlation analysis is performed to identify their individual interactions with spring streamflow till nine lagged months and this is exploited as the basis for developing Multiple Linear Regression (MLR) models to examine the extent of the combined impact of these climate drivers on forecasting spring streamflow several months ahead. Several research works were carried out to forecast streamflow and rainfall for different parts of Australia using the climate indices as potential predictors but none of those apply the Multiple Regression analysis to explore the combined impact of climate indices on long lead seasonal streamflow forecast for New South Wales. Four streamflow stations from south-east New South Wales are selected as a case study based on their recorded data length with fewer missing values. The developed models with all the possible combinations, show significantly good results in terms of Pearson correlation(r), Root Mean Square Error (RMSE), Mean Absolute Error (MAE) and Willmott index of agreement (d) where the best models with lower errors give statistically significant correlations as 0.57 for Wee Jasper station, 0.41 Kiosk Station, 0.49 for Mittagan station and 0.51 for Gundagai station. The best MLR models are obtained with lagged periods up to 3 months. It is evident that every time the combined model outperforms the model considering single climate variable in terms of Pearson correlation(r) which ascertains the better predictive skills of MLR models to forecast spring streamflow several months ahead for the study region.
\end{abstract}

Keywords: $\quad M L R, E N S O, P D O, I P O, I O D$, streamflow forecast 


\section{INTRODUCTION}

High climate inconsistency results in even higher inter-annual streamflow variability across Australia which is about twice the other rivers elsewhere in the world (McMahon et al., 1992). As a consequence, it causes much difficulties to the irrigators, agricultural producers, water managers and planners to allocate irrigation water and environmental flows, manage and operate reservoir, supply municipal water, estimate future hydroelectricity supply etc. Therefore, prediction of rainfall and streamflow over long time scales can help in low- risk decision making for water resources management (Abawi and Ludwig, 2005).

El Nino Southern Oscillation (ENSO), which explains the variations in sea surface temperatures (SST) in the Pacific Ocean is one of the key climatological parameters influencing streamflow throughout Australia (Dutta et al., 2006). Chiew et al. (1998) and Piechota et al. (1998) found that ENSO based (SOI and SST) streamflow predictions in eastern Australia were better than the forecasts from climatology.

Kiem et al. (2001) developed a seasonal streamflow forecast model (SSFM) and explored that in southeast Australia SOI is a better predictor for July-September and October-December streamflow and SST is a better predictor for January-March and April-June streamflow. Chiew et al. (2003) indicates that there exists a clear El Nino- streamflow teleconnection across most of Australia which is stronger than the El Nino- Rainfall teleconnection. Southeast Australian rainfall is influenced by four major climate drivers - ENSO, IPO (Inter Decadal Pacific Oscillation), PDO (Pacific Decadal Oscillation), SAM and IOD (Indian Ocean Dipole) (Duc et al., 2017). Wang et al. (2009) applied Bayesian joint probability modelling and identified NINO3.4 to have stronger impact on forecasting eastern Australian rainfall than SOI which is contradictory to Chiew et al. (1998) findings, who proved significant relationship of eastern and north-central Australian rainfall with SOI but could not find any significant correlation with SST anomalies. Another investigation (Kiem et al., 2001) was carried out in the Williams river catchment (New South Wales) to determine the best ENSO classification methods and ENSO indices from SOI, NINO3 and Multivariate ENSO Index (MEI), where MEI outperformed other ENSO indices in discriminating runoff variability.

A recent attempt (Duc et al., 2017) was made using the Bayesian Model Averaging (BMA) method to analyze the combined impact of the four major climate drivers on the rainfall of NSW as well as to compare their relative contributions in the model. The correlations between ENSO phenomenon and seasonal rainfall in central NSW are found to be the strongest during Spring (Mcbride and Nicholls, 1983). A Bayesian Joint Probability model was introduced by Wang et al. (2009) to determine the best predictors for seasonal streamflow forecast and was applied to two catchments of eastern Australia. The greatest achievement in prediction of streamflow was identified during spring when climate anomalies in the Pacific Ocean acted as the best predictor for Murrumbidgee catchment in NSW. Some recent evidences show that Eastern Australia is also influenced by IOD as well as inter-decadal modulation of ENSO as a result of the PDO (Westra et al., 2008). A combination of correlation and wavelet based methods was applied to identify the principal sources of variability of Sydney's reservoir inflows which found ENSO phenomenon and PDO to be responsible with correlation coefficients -0.32 for Nino3.4 and -0.43 for PDO against annual reservoir inflow (Westra et al., 2008). There exists a greater correlation of annual rainfall in Sydney with the PDO index than with SOI (Whiting et al., 2003).

The aim of this study is to develop a seasonal streamflow forecasting method considering the combined impacts of large scale climate drivers. To accomplish the aim of this study, several oceanic and atmospheric climate indices are selected considering their influence on the streamflow of NSW which includes four major climate drivers of this region PDO, IPO, IOD and the ENSO indices. Four streamflow stations from south-east New South Wales are selected and for each station single lagged analysis is performed which is followed by multiple linear regression analysis to identify the best predictor models for forecasting spring streamflow several months ahead in this region.

\section{DATA AND STUDY AREA}

New South Wales is situated in the south-eastern part of Australia. For the current research, the south-east part of New South Wales is selected as the study area. Four streamflow stations (Figure 1) Murrumbidgee River at Gundagai (Station ID 410004), Goodradigbee River at Wee Jasper (Station ID 410024), Murrumbidgree River at Mittagang Crossing (Station ID 410033) and Cotter River at Kiosk (Station ID 410700) are selected based on their long data records and fewer missing values. Observed monthly streamflow in cumec, is collected from Australian Bureau of Meteorology (www.bom.gov.au/climate/data/) for 102 years ranging from 1914 to 2015. These stations have less than $0.5 \%$ missing values which are filled by the series mean of the streamflow data. 85 years' (from 1914 to 1998) of streamflow data was selected for the calibration of the models, while the 
remaining 17 years' (from 1998 to 2015) data was selected for validation in order to assess the future streamflow predictability of the developed MLR models.

Five climate drivers, NINO3.4, EMI, IOD, PDO and IPO have been selected for the current study based on their influences on the climate of the selected region (Duc et al., 2017, Westra et al., 2008 and Whiting et al., 2003). ENSO phenomenon has two components- sea surface temperature and atmospheric pressure which are intensely correlated and can be represented by two types of indicators, the SLP indicator and the SST indicator (Duc et al., 2017). NINO3.4 is the SST anomaly of ENSO that originates in the equatorial Pacific Ocean $\left(5^{\circ} \mathrm{S}\right.$ $\left.5^{\circ} \mathrm{N}, 170^{\circ}-120^{\circ} \mathrm{W}\right)$. The El Niñ Modoki is an ocean-atmosphere coupled process, which results in unique tripolar sea level pressure pattern during the evolution, similar to the Southern Oscillation phenomenon of El Nino (Ashok et al., 2007). Therefore, this phenomenon is named as El Niño-Southern Oscillation (ENSO) Modoki and expressed by the following equation (Ashok et al., 2007).

$$
\mathrm{EMI}=\operatorname{SSTX}-(0.5 * \mathrm{SSTY})-(0.5 * \mathrm{SSTZ})
$$

Where,

$\mathrm{X}=165^{\circ} \mathrm{E}-140^{\circ} \mathrm{W}, 10^{\circ} \mathrm{S}-10^{\circ} \mathrm{N}, \mathrm{Y}=110^{\circ} \mathrm{W}-70^{\circ} \mathrm{W}, 15^{\circ} \mathrm{S}-5^{\circ} \mathrm{N}, \mathrm{Z}=125^{\circ} \mathrm{E}-145^{\circ} \mathrm{E}, 10^{\circ} \mathrm{S}-20^{\circ} \mathrm{N}$

The Dipole Mode Index (DMI) which is a measure of the IOD is defined as the difference in SST anomaly between the tropical western Indian Ocean $(10 \mathrm{oS}-10 \mathrm{oN}$, $50 \mathrm{o}-70 \mathrm{oE})$ the tropical south- eastern Indian Ocean (10oS-equator, $90 \mathrm{o}-110 \mathrm{oE})$. The IPO is described as the Pacific ENSO-like pattern of SST which is found in the analysis of nearglobal inter-decadal SST (Folland et al., 1999). While IPO is defined for the whole Pacific Basin, PDO is defined for the North Pacific, pole ward of $20^{\circ} \mathrm{N}$. The five oceanic and atmospheric climate indices data are obtained from Climate Explorer website (http://climexp.knmi.nl) while the EMI data is collected from the website of JAMSTEC

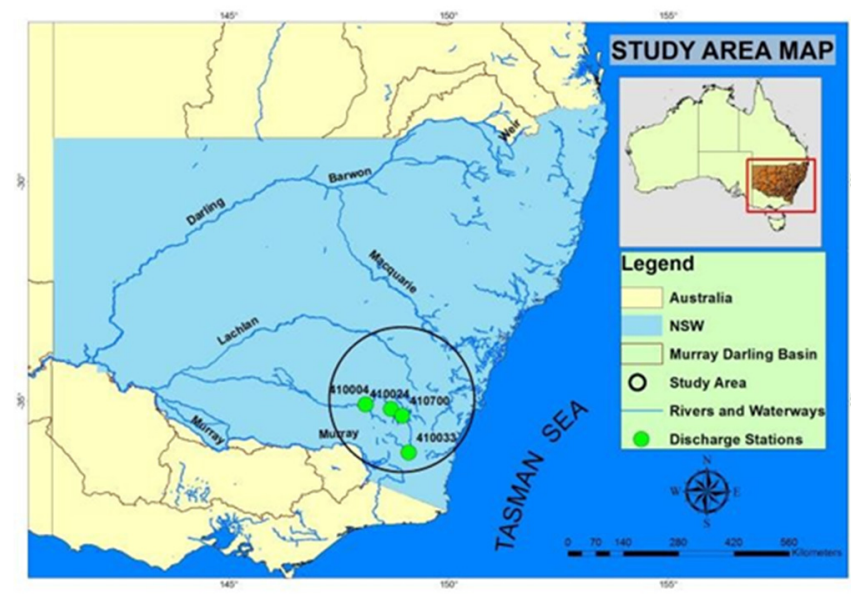

Figure 1. Map of the study area showing the locations of the streamflow stations.

(http://www.jamstec.go.jp/frcgc/research/dl/iod/modoki) for duration of 102 years (1914-2015).

\section{METHODOLOGY}

There are several engineering applications exploring relationship between two or more parameters. Regression analysis model is one of the popular statistical approaches, and is highly recommended for this kind of analysis. Multiple linear regression is the most common form of linear regression analysis. As a predictive analysis, multiple linear regression attempts to model the relationship between two or more explanatory variables and a response variable by fitting a linear equation to observed data. Every value of the independent variable ' $x$ ' is associated with a value of the dependent variable ' $y$ '. In many studies, streamflow forecasting has been undertaken using MLR model, since this model comprises many regressors to deal with the time series data base.

Multiple regression models can be presented by the following equation:

$$
Y=a+b_{1} X_{1}+b_{2} X_{2}+c
$$

where, Y refers to the dependent variable (i.e., spring streamflow for this study), X1 and X2 are two selected independent variables (e.g. NINO3.4, EMI, IOD, PDO or IPO for this study), b1 and b2 are the coefficients of two independent variables, a is constant and $\mathrm{c}$ is intercept or the error.

In the present study, for the purpose of evaluating the goodness-of-fit of the models, the F-test was used to verify the statistical significance of the overall fit. The next statistical criterion that needs to be satisfied while developing a MLR model is evaluation of the statistical significance of the individual parameters of the model.

Multicollinearity verification among the predictors is the important stage of MLR modeling. It occurs when the predictors are highly correlated that result in a dramatic change in parameter estimates in response to small changes in the data or the model. The Variance Inflation Factor (VIF) is used to ascertain the multicollinearity 
Esha and Imteaz, Seasonal streamflow prediction using large scale climate drivers for NSW region

among the predictors. The indicators used to identify multicollinearity among predictors are tolerance $(\mathrm{T})$ and variance inflation factor (VIF):

$$
\text { tolerance }=1-R 2, V I F=1 / \text { tolerance }
$$

Where, R2 is the coefficient of multiple determination:

$$
R 2=S S R / S S T=1-S S E / S S T
$$

Where, SST is the total sum of squares, SSR is the regression sum of squares and SSE is the error sum of squares. According to (Quan et al., 2006), a tolerance of less than $0.20-0.10$ or a VIF greater than 5-10 indicates a multicollinearity problem.

In order to ensure independence of residuals error of the model Durbin- Watson (DW) test is performed, which assesses the serial correlation between errors. DW parameter has a range of 0 to 4; a value of less than 1 or greater than 3 are certainly matter of concern (Field, 2009).

The performance of the developed MLR models have been assessed by several statistical performance measures which are widely used for the evaluation of regression models. Statistical measures namely mean square error (RMSE), mean absolute error (MAE), Pearson correlation coefficient (r) and Willmott index of agreement $(\mathrm{d})$ are exclusively chosen for this study. ' $d$ ' is defined as follows:

$$
d=1-\frac{\left[\sum|y i-x i|^{2}\right]}{\sum\left[(|y i-\bar{x} 1|+|x i-\bar{x} 1|)^{2}\right]}
$$

Where, $y i$ refers to the predicted value corresponding to ith observation and xi refers to ith observation. The closer the ' $d$ ' value to one the better the model fits the observations. The development of multiple linear regression models and all the relevant statistical calculations are performed using the "R Studio 3.3.1" software.

\section{RESULT}

In each of the 4 selected stations of south-east New South Wales, single lag correlation analysis is performed between spring streamflow at year ' $n$ ' and monthly (December ${ }_{n-1}$ to August $t_{n}$ ) values of the climate indices. The outcomes are presented in Table 1, where NINO3.4 is found to have significant correlations up to 7 months' lag (Gundagai station). These findings align with the study of (Wang et al., 2009) who found strong impact of Nino3.4 on spring rainfall in the same study region up to a lag of 2 months. Duc et al. (2017)

\begin{tabular}{|c|c|c|c|c|c|c|c|c|c|c|}
\hline \multirow{2}{*}{ Stations } & \multirow{2}{*}{ Indices } & \multicolumn{9}{|c|}{ Lagged Months } \\
\hline & & Dec $_{n-1}$ & $\operatorname{Jan}_{n}$ & $\mathrm{Feb}_{\mathrm{n}}$ & $\operatorname{Mar}_{n}$ & $\mathbf{A p r}_{\mathrm{n}}$ & May $_{n}$ & June $_{n}$ & July $_{\mathbf{n}}$ & $\operatorname{Aug}_{n}$ \\
\hline \multirow{5}{*}{410024} & NINO 3.4 & & & & & & $-0.27 * *$ & $-0.40 * *$ & $-0.42 * *$ & $-0.40 * *$ \\
\hline & PDO & $-0.21 *$ & $-0.23 *$ & & $-0.19 *$ & $-0.21 *$ & & & $-0.19 *$ & $-0.21 *$ \\
\hline & IOD & & & & & & & $-0.21 *$ & $-0.29 * *$ & $-0.32 * *$ \\
\hline & IPO & $-0.23^{*}$ & $-0.23 *$ & $-0.23 *$ & $-0.23 *$ & $-0.23 *$ & $-0.23 *$ & $-0.23 *$ & $-0.23 *$ & $-0.23 *$ \\
\hline & EMI & & & & & & & & $-0.26 * *$ & $-0.32 * *$ \\
\hline \multirow{3}{*}{410700} & NINO 3.4 & & & & & & $-0.19^{*}$ & $-0.25 * *$ & $-0.35 * *$ & $-0.33^{* *}$ \\
\hline & PDO & $-0.29 * *$ & $-0.31 * *$ & $-0.30 * *$ & $-0.32 * *$ & $-0.26 * *$ & & & & $-0.24 *$ \\
\hline & IOD & & & & & & $-0.21^{*}$ & $-0.22^{*}$ & $-0.34 * *$ & $-0.31 * *$ \\
\hline \multirow{3}{*}{410033} & NINO 3.4 & & & & & & $-0.24 *$ & $0 . \overline{31} * *$ & $-0.28 * *$ & $-0.26 * *$ \\
\hline & PDO & $-0.23 *$ & $-0.26^{* *}$ & $-0.31 * *$ & $-0.37 * *$ & $-0.28 * *$ & & & & $-0.24 *$ \\
\hline & IOD & $-0.33 * *$ & & & $-0.21 *$ & $-0.33 * *$ & $-0.32 * *$ & $0.33 * *$ & $-0.38 * *$ & $-0.36^{* *}$ \\
\hline \multirow{5}{*}{410004} & NINO 3.4 & & & $-0.24 *$ & $-0.24 * *$ & $-0.24 * *$ & $-0.26 * *$ & $0.31 * *$ & $-0.34 * *$ & $-0.29 * *$ \\
\hline & PDO & $-0.26 * *$ & $-0.26^{* *}$ & $-0.28 * *$ & $-0.31 * *$ & $-0.27 * *$ & $-0.22 *$ & $0 . \overline{24} * *$ & $-0.22 *$ & $-0.21 *$ \\
\hline & IPO & & $-0.25^{* *}$ & $-0.25 * *$ & $-0.25 * *$ & $-0.25 * *$ & $-0.25 * *$ & $0.25 * *$ & $-0.25 * *$ & $-0.25 * *$ \\
\hline & IOD & & & & & & $-0.19^{*}$ & $-0.23 *$ & $-0.25^{* *}$ & $-0.25 * *$ \\
\hline & EMI & & & & & & & & $-0.20^{*}$ & \\
\hline
\end{tabular}
explained that ENSO indices have strong impact on rainfall during Austral spring.

Table 1. Pearson correlations (r) of lagged climate indices and spring streamflow

It is explored that PDO has statistically significant correlation up to nine months' lag for all four stations. This is similar to the assessment of Whiting et al. (2003) who discovered that PDO has greater correlation with 
annual rainfall of Sydney than that of SOI. Westra et al. (2008) where spring inflow correlations for Nino3.4 and PDO were found to be -0.17 and -0.19 respectively.

Various models with different lagged months' indices are analyzed for the four stations (Table 2) in order to find out the best forecasting model. For all the station, the best models with lower errors while satisfying the statistical limits are selected. F-test is performed to evaluate the best model that fits the population of the sample data while the t-test is conducted to identify the significance of the individual parameters. The best model for each station with their regression coefficients, variance inflation factor (VIF), Durbin-Watson statistics (DW) and the Pearson correlation (r) are presented in Table 2.

Table 2. Summary of the best MLR models

\begin{tabular}{|c|c|c|c|c|c|c|}
\hline Station Name & Model & Constant & Coefficient & $\mathbf{r}$ & Durbin- Watson & VIF \\
\hline Wee Jasper & $\mathrm{IOD}_{\text {JULY_NINO3.4 JULY }}$ & 14.70 & $\begin{array}{l}-3.15 \\
-4.80\end{array}$ & 0.42 & 1.76 & 1.17 \\
\hline Kiosk & $\mathrm{PDO}_{\mathrm{AUG} \_} \mathrm{NINO}_{3.4_{\mathrm{JULY}}}$ & 5.91 & $\begin{array}{l}-0.54 \\
-2.68\end{array}$ & 0.45 & 1.73 & 1.30 \\
\hline Mittagang Crossing & $\mathrm{PDO}_{\mathrm{AUG} \_\mathrm{NINO}} 3.4_{\mathrm{JULY}}$ & 13.16 & $\begin{array}{l}-1.90 \\
-2.54 \\
\end{array}$ & 0.35 & 1.16 & 1.30 \\
\hline Gundagai & $\mathrm{IPO}_{\text {JULY_NINO3.4 JULY }}$ & 158.12 & $\begin{array}{l}-18.76 \\
-42.94 \\
\end{array}$ & 0.43 & 1.83 & 1.05 \\
\hline
\end{tabular}

*Correlation is significant at $0.05 \%$ level

Table 3. Performance test for the best-developed model for calibration and validation period

\begin{tabular}{|c|c|c|c|c|c|c|c|c|c|}
\hline \multirow{2}{*}{$\begin{array}{l}\text { Station } \\
\text { Name }\end{array}$} & \multirow{2}{*}{ Model } & \multicolumn{4}{|c|}{ Calibration Period } & \multicolumn{4}{|c|}{ Validation Period } \\
\hline & & $\mathbf{r}$ & RMSE & MAE & d & $\mathbf{r}$ & RMSE & MAE & d \\
\hline $\begin{array}{c}\text { Wee } \\
\text { Jasper }\end{array}$ & $\mathrm{IOD}_{\mathrm{JUL}} \mathrm{NINO} .4_{\mathrm{JUL}}$ & 0.45 & 7.51 & 6.04 & 0.53 & 0.57 & 5.47 & 4.39 & 0.63 \\
\hline Kiosk & $\mathrm{PDO}_{\mathrm{AUG} \_} \mathrm{NINO} 3.4_{\mathrm{JUL}}$ & 0.45 & 3.98 & 3.04 & 0.57 & 0.41 & 4.24 & 3.74 & 0.52 \\
\hline $\begin{array}{l}\text { Mittagang } \\
\text { Crossing }\end{array}$ & $\mathrm{PDO}_{\mathrm{AUG}} \mathrm{NINO}_{-} .4_{\mathrm{JUL}}$ & 0.35 & 8.91 & 7.41 & 0.44 & 0.49 & 9.73 & 9.30 & 0.38 \\
\hline Gundagai & $\mathrm{IPO}_{\text {JUL_NINO3.4 JUL }}$ & 0.43 & 71.40 & 58.0 & 0.55 & 0.51 & 72.37 & 66.03 & 0.40 \\
\hline
\end{tabular}

*Correlation is significant at $0.05 \%$ level

It is seen from the Table 2 that VIF values for the selected models are close to one, which refers that there is no multi-collinearity problem between the predictors. According to Field (2009), values less than 1 or greater than 3 for DW test will indicate the presence of serial correlations between the model errors. So, it can be concluded from the results of Table 2 that the DW test of each selected model satisfies the statistical limit which also establishes the goodness of fit of the models.

It is evident from the current analysis that the selected models are not only statistically significant but also have the potential to predict the spring streamflow of south-east New South Wales with the highest correlation of 0.57 (at validation stage) for Wee Jasper Station. The best models are obtained with 2 months' lag period. Table 3 shows the performance statistics of RMSE, MAE, index of agreement and Pearson correlation (r) of the best developed models for the calibration and validation periods. It is clearly evident from Table 3 that there is significant increment of the correlation values from calibration to validation stage for instance, ' $r$ ' increases from 0.42 in calibration period to 0.57 in validation period at Wee Jasper station. The capability of the developed models for forecasting spring streamflow with higher accuracy has been ensured as the values of RMSE, MAE and d in the validation period show good agreement with the calibration period. Significant increment of the Pearson correlation values has explained that the combined models have greater skills for predicting streamflow than the single lagged indices. For example, at Wee Jasper station, while the single Nino3.4 and IOD models with 2 months' lead time had a correlation(r) -0.42 and -0.29 respectively, the predictability was significantly enhanced by the combined contribution of these two indices with two months' lead time in the MLR analysis ( $\mathrm{r}=0.57)$. Four of the selected indices NINO3.4, IOD, PDO and IPO were proved to be influential on spring streamflow of south eastern NSW whereas, little or no influence of EMI was found on spring streamflow of the study regions. The ability of the MLR models to simulate observed streamflow as 
well as to predicted future streamflow have been explained through the time series plots in Figure 2. In the time series plots, some over-estimations of the models are observed during the validation stage which, may be resulted from the "millennium drought" (Bond et al., 2008) periods that occurred from 1994 to 2010 over the continent. It was explored by Kiem et al. (2009) that a combination of climate drivers in the Pacific Ocean (ENSO, PDO), IOD and SAM were responsible for the past three droughts in south-east Australia; the 'Federation' drought (1895-1902), the 'World War II' drought (1937-1945) and the 'Big Dry' (19942010). A model based on only two climate indices (Nino3.4 and PDO) is not likely to replicate an unusual phenomenon like "millennium drought". This can also be the reason of not reflecting the unusually high rainfall of 1950 of NSW in the time series plots, where the difference between the simulated and observed flow is found to be high (Vandome et al., 2001).

A comparison with the previous studies of forecasting streamflow is shown in Table 4 where it is that the combined MLR model show better agreement with streamflow compared to the single correlation analysis of different climate indices with streamflow.

\section{CONCLUSION}

In this study, an effort is made to explore the potential skill of the combined climate indices to forecast spring streamflow of south-east New South Wales with a longer lead time than the usual practice. In order to identify the best combination of predictors, Multiple Linear Regression models are developed based on the individual lagged correlation of each climate variable with spring streamflow.



(a)

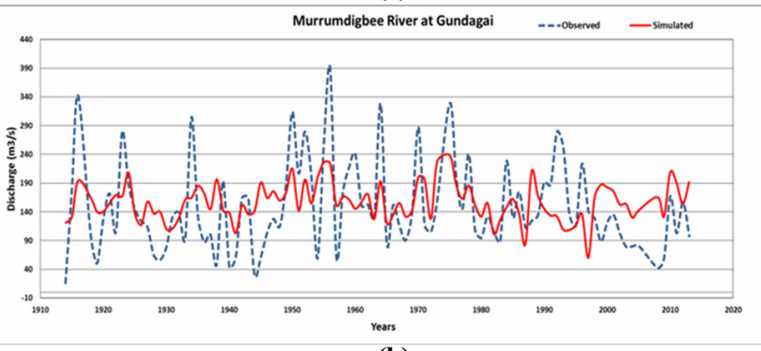

(b)

Figure 2: Comparison between the observed and simulated streamflow during the calibration (1914-1998) and validation (1999-2015) periods for Wee Jasper Station and (b) Gundagai Station

Table 4. Comparison with the previous studies based on highest correlations between indices and spring streamflow for South-East Australia

\begin{tabular}{|c|c|c|c|c|}
\hline \multirow[t]{2}{*}{ INDICES } & \multirow{2}{*}{$\begin{array}{c}\text { Kirono } \\
\text { et al. } \\
(2010)\end{array}$} & \multirow{2}{*}{$\begin{array}{l}\text { Chiew et } \\
\text { al. (2003) }\end{array}$} & \multicolumn{2}{|c|}{ Current Study } \\
\hline & & & $\begin{array}{c}\text { Single } \\
\text { lagged } \\
\text { correlation }\end{array}$ & $\begin{array}{c}\text { MLR } \\
\text { correlation }\end{array}$ \\
\hline Nino3.4 & - & - & $-0.42_{\mathrm{iv}}$ & $0.57_{\text {viii }}$ \\
\hline IOD & - & - & $-0.38 v$ & \\
\hline Nino3 & $0.35 i$ & - & $-0.32 \mathrm{vi}$ & \\
\hline SOI & $0.36_{\mathrm{ii}}$ & $0.51_{\mathrm{iii}}$ & $-0.53_{\mathrm{vii}}$ & \\
\hline
\end{tabular}

i) 8 months lagged $\mathrm{Nino} 3$ iii) Winter SOI

v) 2 months lagged IOD ii) 12 months lagged SOI

iv) 2 months lagged Nino3.4

vi) 3 months lagged Nino3.4

Further statistical analysis has been carried out for each combination of climate variables for different lagged months and the models that produce higher correlation ( $\mathrm{r}$ ) with spring streamflow as well as satisfy all the statistical limits significantly during both the calibration and validation periods, are proposed to be the best combined models for the corresponding stations.

Four of the selected indices (NINO3.4, PDO, IOD and IPO) have shown statistically significant correlations up to nine months' lag for all the four stations during their single lagged analysis which, ultimately generate a good number of combinations for the MLR analysis. The developed models with all the possible combinations show significantly good results in terms of Pearson correlation (r), Statistical error analysis (RMSE and MAE) and $d$ value, where the best models with lower errors give statistically significant correlations as high as 0.57 for Wee Jasper Station, 0.41 for Kiosk station, 0.49 for Mittagang Crossing and 0.69 for the Murrumbidge Station. It is noteworthy that every time the combined model outperforms the models considering single climate variable in terms of Pearson correlation (r), which is the evidence of better predictive skills of the MLR models.

As NINO3.4, PDO, IOD and IPO are the major climate drivers of NSW, the model accounting their combined effect can be one of the key tools for predicting seasonal streamflow for this region. The interactions between other climate variables and streamflow of different seasons in all regions of NSW will be effective measure of solving water management problem and such analysis will be attributed to our future research. 
Esha and Imteaz, Seasonal streamflow prediction using large scale climate drivers for NSW region

\section{REFERENCES}

Abawi, G. S. and Ludwig, J. W. (2005). Effect of three crop rotations with and without deep plowing on root rot severity and yield of beans. ANNUAL REPORT-BEAN IMPROVEMENT COOPERATIVE, 48, 118.

Ashok, K., Behera, S. K., Rao, S. A., Weng, H., and Yamagata, T. (2007). El Niño Modoki and its possible teleconnection. Journal of Geophysical Research: Oceans, 112(C11).

Bond, N. R., Lake, P. S., and Arthington, A. H. (2008). The impacts of drought on freshwater ecosystems: an Australian perspective. Hydrobiologia, 600(1), 3-16.

Chiew, F. H., Piechota, T. C., Dracup, J. A., and McMahon, T. A. (1998). El Nino/Southern Oscillation and Australian rainfall, streamflow and drought: Links and potential for forecasting. Journal of Hydrology, 204(1-4), 138-149.

Chiew, F. H. S., and Leahy, M. J. (2003). Inter-decadal Pacific oscillation modulation of the impact of El Niño/Southern Oscillation on Australian rainfall and streamflow. In MODSIM 2003: International Congress on Modelling and Simulation, Vol 1, 100-105.

Chiew, F. H. S., Zhou, S. L. and McMahon, T. A. (2003). Use of seasonal streamflow forecasts in water resources management. Journal of Hydrology, 270(1), 135-144.

Chiew, F. H. S., Teng, J., Vaze, J., Post, D. A., Perraud, J. M., Kirono, D. G. C., and Viney, N. R. (2009). Estimating climate change impact on runoff across southeast Australia: Method, results, and implications of the modeling method. Water Resources Research, 45(10).

Dutta, S. C., Ritchie, J. W., Freebairn, D. M. and Abawi, G. Y. (2006). Rainfall and streamflow response to El Niño Southern Oscillation: a case study in a semiarid catchment, Australia. Hydrological sciences journal, 51(6), 1006-1020.

Duc, H. N., Rivett, K., MacSween, K., and Le-Anh, L. (2017). Association of climate drivers with rainfall in New South Wales, Australia, using Bayesian Model Averaging. Theoretical and Applied Climatology, 127(1-2), 169-185.

Folland, C. K., Parker, D. E., Colman, A. W., and Washington, R. (1999). Large scale modes of ocean surface temperature since the late nineteenth century. In Beyond El Niño (pp. 73-102). Springer Berlin Heidelberg.

Field, A. (2009). Discovering statistics using SPSS. Sage publications.

Kiem, A. S., and Verdon-Kidd, D. C. (2009). Climatic drivers of Victorian streamflow: is ENSO the dominant influence?. Australian Journal of Water Resources, 13(1), 17-29.

Kirono, D. G., Chiew, F. H., and Kent, D. M. (2010). Identification of best predictors for forecasting seasonal rainfall and runoff in Australia. Hydrological processes, 24(10), 1237-1247.

McBride, J. L., and Nicholls, N. (1983). Seasonal relationships between Australian rainfall and the Southern Oscillation. Monthly Weather Review, 111(10), 1998-2004.

McMahon, T. A., Finlayson, B. L., Haines, A. T. and Srikanthan, R. (1992). Global runoff: continental comparisons of annual flows and peak discharges. Catena Verlag.

Piechota, T. C., Chiew, F. H., Dracup, J. A., and McMahon, T. A. (1998). Seasonal streamflow forecasting in eastern Australia and the El Niño-Southern Oscillation. Water Resources Research, 34(11), 3035-3044.

Quan, X., Hoerling, M., Whitaker, J., Bates, G., and Xu, T. (2006). Diagnosing sources of US seasonal forecast skill. Journal of climate, 19(13), 3279-3293.

Vandome, F., Miller, F. P., and McBrewster, J. (2011). 1950 Australian Rainfall Records. Mauritius, Betascript Publishing

Whiting, J. P., Lambert, M. F., and Metcalfe, A. V. (2003). Modelling persistence in annual Australia point rainfall. Hydrology and Earth System Sciences Discussions, 7(2), 197-211.

Westra, S., Sharma, A., Brown, C., and Lall, U. (2008). Multivariate streamflow forecasting using independent component analysis. Water Resources Research, 44(2).

Wang, Q. J., Robertson, D. E., and Chiew, F. H. S. (2009). A Bayesian joint probability modeling approach for seasonal forecasting of streamflows at multiple sites. Water Resources Research, 45(5). 